of effective guidelines. One prerequisite is an ongoing review of evidence on the outcome of different approaches to management. This has been done for perinatal care and so far over 5000 perinatal trials have been identified and classified. ${ }^{11}$ Guidelines should be based on the best available evidence, and assembling this is hard work. Help is at hand. The proposed Cochrane Centre will have an important role in fostering systematic, up to date reviews of controlled trials (see next editorial). ${ }^{12}$ Leeds has a clearing house for assessing health services' outcomes, which circulates a quarterly bulletin. ${ }^{13}$ In future, a guideline coordinating centre could collaborate closely with the royal colleges, which have already worked in this area, ${ }^{14-16}$ and other local, national, and international bodies.

Guidelines are not static and must be continually updated to take account of changes in medical knowledge and practice and particularly the results of randomised trials and meta- analyses. At the same time, guidelines must honestly reflect the large areas of uncertainty in the management of many conditions and not attempt to stifle healthy variation in practice. ${ }^{17}$ By indicating areas in which evidence is incomplete or inadequate, they can help to identify priorities for research and by pointing out where evidence is strong they can improve care for patients.

ANDREW HAINES

University College and Middlesex

School of Medicine,

Whittington Hospital

London N19.5NF

GENE FEDER

Department of General Practice, Research Fellow

St Bartholomew's and The London Hospitals

Medical College,

London EC1 6BQ
1 Royal College of Radiologists Working Party. Influence of the Royal College of Radiologists guidelines on hospital practice: a multicentre study. $B M \mathcal{F}$ 1992;304:740-3.

Vos Meiring PD, Wells IP. The effect of radiology guidelines for general practitioners in Plymouth Clin Radiol 1990;42:327-9.

3 North of England Study of Standards and Performance in General Practice. Medical audit in general practice. 1. Effects on doctors' clinical behaviour for common childhood conditions. BMF 1992;304:1480-4.

4 North of England Study of Standards and Performance in General Practice. Medical audit in general practice. 2. Effects on health of patients with common childhood diseases. BMJ 1992;304:1484-8.

5 Russell I, Grimshaw J. The effectiveness of referral guidelines: a review of the methods and findings of published evaluations. In: Roland M, Coulter A, eds. Hospital referrals. Oxford: Oxford University Press, 1992

6 Marinker M. Standards. In: Medical audit and general practice. London: BMJ, 1991:15-25.

7 Lomas MA, Anderson GM, Demnick-Pierre K, Vayda E, Enkin MW, Hannah WJ. Do practice Lomas MA, Anderson GM, Demnick-Pierre K, Vayda E, En
guidelines guide practice? N Engl 7 Med 1989;321:1306-11.

8 Kosecoff J, Kanouse DE, Rogers WH, McCluskey L, Winslow CM. Brook RH. Effects of National Institutes of Health consensus development program on physician practice. JAMA $_{A}$ Institutes of $\mathrm{He}$
9 Grol R. National standard setting for quality of care in general practice: attitudes of general practitioners and response to a set of standards. Br f Gen Pract 1990;40:361-4.

Brook RH. Practice guidelines and practicing medicine. Are they compatible? A AMA 1989;262:3027-30

1 Chalmers I. Improving the quality and dissemination of reviews of clinical research. In Lock S, ed The future of medical journals. London: BMJ, 1991.

2 Chalmers I, Dickersin K, Chalmers TC. Getting to grips with Archie Cochrane's agenda. BMf 1992;305:786-8

3 Lond AF, Bate L, Sheldon TA. Establishment of a UK clearing house for assessing health services outcomes. Quality in Health Care 1992;1:131-3.

4 Research Unit of the Roval College of Physicians and the British Geriatrics Society. Standardised assessment scules for elderly people. London: Royal College of Physicians of London, British Geriatrics Society, 1992.

15 Royal College of General Practitioners. Asthma; depression; diabetes; rheumatoid arthritis; schizophrenia; terminal care. London: RCGP, 1986-9. (Information folders.)

phrenia; terminal care. London: RCGP, 1986-9. (Information folders.)
Haines A, Hurwitz B. Guidelines for the management of common medical conditions. London: Roval College of General Practitioners (in press).

17 Guidelines for doctors in the new world [editorial]. Lancet 1992;339:1197-8.

\title{
Getting to grips with Archie Cochrane's agenda
}

\author{
All randomised controlled trials should be registered and reported
}

It is surely a great criticism of our profession that we have not organised a critical summary, by specialty or subspecialty, updated periodically, of all relevant randomised controlled trials.

Archie Cochrane

Twenty years ago, in Effectiveness and Efficiency, Archie Cochrane emphasised the importance of randomised controlled trials in guiding decisions about health care. ${ }^{1}$ Randomised trials are not always required to assess the effects of health care (the good and bad effects of some forms of health care are obvious), and sometimes trials are not feasible. But, for many forms of care, trials involving sufficient numbers of participants are essential to distinguish reliably between the effects of care and the effects of biases or chance. Just as important as conducting the trials, though, is disseminating the results through systematic reviews of the findings. Such reviews depend on the difficult task of identifying all relevant trials, and several efforts are going on internationally to coordinate this work.

If people are to benefit from the results of trials all the steps between research and practice must be accomplished effectively. Trials must be properly designed, conducted, analysed, and reported. Their results must be assembled in systematic, up to date, and accessible reviews. The results of these reviews must be taken into account by decision makers, and finally, based on these decisions, there must be effective systems to audit how well local or national guidelines for health care are followed.

Currently weaknesses exist at all these steps. Cochrane drew attention to a particular weakness, however, when he criticised the medical profession for not having organised a system for producing up to date reviews of the results of randomised controlled trials. Experience gained over the past decade provides a useful basis for developing such a system. ${ }^{2}$ In particular, it has become clear that the same scientific principles that are applied to the design and conduct of primary research must also be applied to the process of reviewing that research. ${ }^{34}$

Impressive examples now exist of the power of systematic reviews to provide reliable answers to important questionsfor example, the effects of treatment on early breast cancer. ${ }^{5}$ Recent studies have shown that if systematic reviews, updated periodically, had been started at the beginning of a series of related trials reliable recommendations for treatment would have been made earlier. ${ }^{6}$ Unsystematically conducted reviews in journals and textbooks have sometimes taken more than a decade to recommend treatments that a systematic review of trials would have shown to prevent premature death; in addition, other treatments have been endorsed long after evidence from trials had suggested that they were useless or actually harmful.

The usual, unsystematic approach to reviewing the effects of care $^{3}$ also increases the probability that resources will be 
wasted. For example, a systematic review of randomised controlled trials a decade ago would have shown that a short course of corticosteroids given to mothers expected to give birth prematurely substantially reduces the risk of neonatal morbidity and death. ${ }^{8}$ Repeated failure to conduct, and apply the results of, systematic reviews of these trials has not only resulted in the unnecessary suffering of tens of thousands of babies but has also meant that neonatal care has been more expensive than it need have been. ${ }^{9}$ Similarly, research funding bodies and ethics committees should be concerned about the extent to which resources are wasted on unnecessary research-for example, in repeated demonstrations of the protective effects of prophylactic antibiotics for some forms of surgery. ${ }^{10}$

For all of these reasons, continuing inefficiencies in reviewing the results of controlled trials are disturbing. Although ways of tackling this problem are not difficult to conceptualise, several daunting practical challenges confront anyone trying to get to grips with Cochrane's agenda.

The most fundamental challenge is to identify all of the potentially relevant studies. Complete identification, even of published reports of controlled trials, continues to be remarkably difficult. For example, electronic searching for controlled trials with the National Library of Medicine's database MEDLINE usually retrieves only about half the relevant studies. ${ }^{11}$ Most of the articles missed are in fact contained in MEDLINE but are inaccurately indexed, either because authors have not described their research methods clearly or because the library's own coding procedures have not been properly applied.

An even more difficult problem results from underreporting of some trials, possibly by as much as $50 \%$ in some disciplines. ${ }^{12}$ This underreporting exists mainly because investigators never submit manuscripts for publication, not because referees or editors reject them. ${ }^{12-14}$ Sometimes trials are reported only as published abstracts or letters to the editor $^{15-16}$ or in unindexed conference proceedings, poster presentations, or unrecorded oral presentations.

Sometimes lengthy reports of trials are prepared but gather dust as unpublished degree theses, unindexed technical reports, or other forms of "grey literature." Some are never publicly reported at all. This phenomenon is particularly alarming because unpublished trials may have systematically different results from those that are published. ${ }^{12-1417}$ This publication bias obviously increases the chances that reviews based only on published reports will themselves be biased and will in turn promote inappropriate health care.

What can be done about this undesirable state of affairs? To identify published reports of controlled trials there currently seems no alternative to using various different search strategies. The best methods, unfortunately, may require time consuming searches of relevant journals by hand and extensive inquiries to track down unpublished studies.

One of the functions of the Cochrane Centre, established this month as part of the NHS's research and development programme to facilitate systematic reviews of randomised trials, will be to collaborate with others to assemble and disseminate a register of controlled trials. This should help those conducting systematic reviews by reducing unnecessary duplication of effort and maximising the identification of relevant trials. We invite investigators, professional organisations, specialty groups, funding bodies (including industry), editors, and others to contact us to receive further details about our activities, to provide bibliographies of randomised controlled trials for inclusion in the register, and to suggest other ways of improving the current unsatisfactory situation.

Two further developments are needed. Firstly, authors and editors must make it easier for people to identify relevant trials by providing sufficient detail about how comparison groups were generated. Secondly, deficiencies in MEDLINE and other bibliographies of clinical research must be acknowledged and corrected. The wider adoption of structured abstracts is likely to be particularly useful. ${ }^{18}$

The problem of unpublished or incompletely published trials remains difficult. A prerequisite for any solution is that the widespread practice of underreporting the results of well conducted trials should be seen for what it is-namely, scientific misconduct. ${ }^{19}$ Clearly, the resolution of the problem of underreporting lies mainly in the hands of investigators and those who fund and enable their research. ${ }^{12-1420}$

If researchers, funding bodies, and research ethics committees are to take properly informed decisions about proposals for new research they need both the results of systematic reviews and information about trials that are currently recruiting patients. In this way, inadvertent and unnecessary duplication of research (as distinct from planned and appropriate replication) can be reduced. Reasonably complete ascertainment of all trials seems likely only through some form of mandatory registration of studies at the time they are started. ${ }^{2122}$ Although several registries exist, ${ }^{24}$ most remain incomplete because they depend on voluntary notification. Funding agencies and ethics committees should require the registration and publication of trials that they have supported and approved.

Encouraging signs exist in several countries of an interest in establishing systems for registering randomised controlled trials at their inception, and there is certainly scope for collaboration. ${ }^{25}$ Within Britain the information systems strategy being developed by the NHS's research and development programme, the registration of cancer trials fostered by the United Kingdom Coordinating Committee for Cancer Research, and the Medical Research Council's inventory of controlled trials together provide a useful basis for developing systems to ensure that information about current randomised controlled trials is assembled more efficiently.

As Archie Cochrane pointed out many years ago, failing to conduct systematic, up to date reviews of controlled trials of health care may result in substantial adverse consequences for patients, practitioners, the health services, researchers, and research funding bodies. Reliable and informative reviews depend on identifying as many relevant studies as possible. Achieving this should be possible by registering trials at their inception, minimising underreporting of trials, improving descriptions of research methods in reports of trials, and better indexing in databases of completed and current research.

IAIN CHALMERS Director

Cochrane Centre,

NHS Research and Development Programme,

Oxford OX2 7LG

KAY DICKERSIN Associate Editor

Online fournal of Current Clinical Trials,

Department of Epidemiology and Preventive Medicine,

University of Maryland School of Medicine,

660 West Redwood St, Baltimore, Maryland 21201, USA

THOMAS C CHALMERS

Deputy Editor

Online fournal of Current Clinical Trials,

Technology Assessment Group,

Harvard School of Public Health

677 Huntington Ave, Boston,

Massachusetts 02115, USA

1 Cochrane AL. Effectiveness and efficiency. Random reflections on health services. London: Nuffield Provincial Hospitals Trust, 1972

2 Chalmers I. Improving the quality and dissemination of reviews of clinical research. In Lock S, ed. The future of medical journals. London: BMF, 1991:127-46. 
3 Mulrow CD. The medical review article: state of the science. Ann Intern Med 1987; 106:485-8. 4 Haynes RB. Clinical review articles. BMF 1991;304:330-1.

5 Early Breast Cancer Trialists' collaborative Group. Systemic

hormonal, cytotoxic, or immune therapy. Lancet 1992;339:1-15.

6 I fancer by a J analysis of her

7 Antman EM, Lau J, Kupelnick B, Mosteller F, Chalmers TC. A comparison of results of metaanalyses of randomized control trials and recommendations of clinical experts. Treatment for myocardial infarction. FAMA 1992;268:240-8.

8 Crowley P, Chalmers I, Keirse MJNC. The effects of corticosteroid administration before preterm delivery: an overview of the evidence from controlled trials. Br $\mathcal{F}$ Obstet Gynaecol 1990;97:11-25.

9 Mugford M, Piercy J, Chalmers I. Cost implications of different approaches to the prevention of respiratory distress syndrome. Arch Dis Child 1991;66:757-64.

10 Baum ML, Anish DS, Chalmers TC, Sacks HS, Smith H, Fagerstrom RM. A survey of clinical trials of antibiotic prophylaxis in colon surgerv: evidence against further use of no-treatment controls. N Engl f Med 1981;305:795-9.

11 Scherer RW, Dickersin K, Kaplan E. The accessible biomedical literature represents a fraction of all studies in a field. Paper presented at the workshop for editors of refereed scientific journals, Nashville, Tennessee, March 1992.

12 Easterbrook PJ, Berlin JA, Gopalan R, Matthews DW. Publication bias in clinical research. Lancet $1991 ; 337: 867-72$.
13 Dickersin K, Chan S, Chalmers TC, Sacks HS, Smith H, Jr. Publication bias and clinical trials. Controlled Clin Trials 1987;8:33-53.

14 Dickersin K, Min YI, Meinert CL. Factors influencing publication of research results: followup of applications submitted to two institutional review boards. FAMA 1992;263:374-8.

15 Chalmers I, Adams M, Dickersin K, Hetherington J, Tarnow-Mordi W, Meinert C, et al. A cohor study of summary reports of controlled trials. FAMA 1990;263:1401-5.

16 Scherer R, Dickersin K. Publication of randomized clinical trials in vision research submitted as abstracts to national ophthalmology meetings. Controlled Clin Trials (in press)

17 Simes RJ. The case for an international registry of clinical trials. $\mathcal{F}$ Clin Oncol 1986;4: 1529-41.

18 Haynes RB, Mulrow CD, Huth EJ, Altman DG, Gardner MJ. More informative abstracts revisited. Ann Intern Med 1990;113:69-76.

19 Chalmers I. Underreporting research is scientific misconduct. FAMA 1990;263:1405-8.

20 Chalmers I, Soll R. Progress and problems in establishing an international registry of perinatal trials (IROPT). Controlled Clin Trials 1991:12:630.

1 Dickersin K, for the Panel. Report from the panel on the case for registers of clinical trials at the eighth annual meeting of the Society for Clinical Trials. Controlled Clin Trials 1988;9:76-81.

22 Hetherington J, Dickersin K, Chalmers I, Meinert C. Retrospective and prospective identification of unpublished controlled trials: lessons from a survey of obstetricians and pediatricians. Pediatrics 1989;84:374-80.

23 Easterbrook PJ. Directory of registries of clinical trials. Stat Med 1992;11:345-423.

24 Dickersin K. Why register clinical trials? Revisited. Controlled Clin Trials 1992:13:170-7.

25 Making clinical trialists register. Lancet 1991;338:244-5.

$4_{17}$

\title{
Breast feeding and HIV infection
}

\author{
Advice depends on the circumstances
}

Breast milk may transmit HIV, though the exact risk of transmission is unknown and varies with circumstances. The European collaborative study group has calculated the overall risk of transmission of virus from infected mother to child as $14 \%$ with breast feeding doubling this figure. ${ }^{1}$ When mothers acquire the infection postnatally the risk of transmission is $29 \% .^{2}$

Virus containing cells may be transmitted in colostrum and breast milk during lactation, although the exact mode of transmission remains unclear. Transmission varies with the stage of HIV infection in the mother and increases during the viraemia that occurs during primary HIV infection and later with progression to AIDS. Evidence for transmission at the time of a primary HIV infection during lactation comes from a Rwandan study of babies who seroconverted while being breast fed. The rate of postnatal transmission from mother to child was estimated at $60 \%$. $^{3}$

In the debates about the risks of transmitting HIV by breast feeding the risks of not breast feeding have received insufficient attention. In many poor communities breast feeding is not merely "baby friendly" but essential for survival. Even in developed countries breast feeding protects against diarrhoea and respiratory infection. ${ }^{6}$ Where there is poverty and poor hygiene these risks are much greater; "the fate of newborn infants in many pre-industrial areas seems to depend largely on whether they are breast fed or not-either they are nursed or they die." In a Brazilian study Victoria et al found that the relative risk of infant death from common infections was much higher in those who had not been breast fed (14.2 times the risk of death from diarrhoea and 3.6 times the risk of death from respiratory infections than in those who were breast fed) ${ }^{8}$ The risk of death from all other causes was also 2.5 times greater in those receiving no breast milk.

The pernicious synergistic effect of not breast feeding and poor sanitation has been shown in Malaysia. ${ }^{9}$ In homes without piped water or a toilet, infants who were not breast fed were five times more likely to die after 1 week of age than those who were breast fed. In homes with these amenities infants who were not breast fed were still 2.5 times more likely to die than those who were. These studies are from South America and Asia; in many African countries affected by AIDS people are even more impoverished, women have less education, breast feeding is the cultural norm, and switching to artificial feeding would increase the toll of infant deaths even more than in Asia and South America. ${ }^{+}$

Artificially feeding infants of mothers with HIV infection should decrease the vertical transmission rate and therefore the morbidity, mortality, and costs of paediatric AIDS. In developed countries where milk powder is relatively cheap, clean water is almost universal, and facilities for cleaning and sterilising bottles are widely available, artificial feeding is relatively safe and the logical choice. In contrast, in Africa where HIV infection is common, artificial feeding is dangerous and costly. Relatively few homes have access to a safe water supply. Fuel for sterilising water and feeding bottles is expensive and scarce. Formula milk is prohibitively expensive for households and countries alike. In a recent survey of seven African countries, the cost of feeding a 3 month old baby $800 \mathrm{ml}$ of commercial breast milk substitute a day varied between $27 \%$ (Zimbabwe) and $900 \%$ (Uganda) of the daily wage of a hospital cleaner (Hofvander et al, personal communication). The public and primary health care services of these countries have suffered with the economic constraints of debt, so the possibility of providing better water supplies and sanitation are remote.

In relatively wealthy communities with sound health services the infants of HIV positive mothers should not be breast fed. Advising HIV positive mothers in poor communities on feeding is much more difficult. Mathematical modellers have been busy. ${ }^{1011}$ They conclude that for Africa, even in the most pessimistic scenarios of a high maternal prevalence of HIV and a high rate of transmission by breast feeding, the risk of death in children is less from breast feeding than from not breast feeding. This supports the most recent WHO recommendation that "where the primary causes of infant deaths are infectious diseases and malnutrition breast feeding should remain the standard advice given to women, including those who are known to be HIV infected". ${ }^{12}$ Most poor, HIV positive mothers will never hear the guidelines nor comprehend the mathematical models. They will continue to feed their babies in the most convenient, economic, and familiar way - at the breast. For their children breast is still best.

Honorary Consultant Paediatrician,

Department of Child Life and Health,

WILLIAM A MICUTTING

University of Edinburgh,

17 Hatton Place,

(Edinburgh)EH9 1UW 